06

\title{
Композиты на основе полистирола с включениями алюмосиликатов различной формы
}

\author{
() О.А. Москалюк, ${ }^{2}$ И.В. Семенова, ${ }^{1,}$ В.Е. Юдин, ${ }^{3}$ Я.М. Бельтюков, ${ }^{1}$ Н.Н. Сапрыкина, ${ }^{3}$ В.Ю. Елоховский ${ }^{3}$ \\ ${ }^{1}$ Физико-технический институт имени А.Ф. Иоффре РАН, \\ 194021 Санкт-Петербург, Россия \\ ${ }^{2}$ Санкт-Петербургский государственный университет промышленных технологий и дизайна, \\ 191186 Санкт-Петербург, Россия \\ ${ }^{3}$ Институт высокомолекулярных соединений РАН, \\ 199004 Санкт-Петербург, Россия \\ ฯ e-mail: irina.semenova@mail.ioffe.ru
}

(Поступило в Редакцию 14 июня 2018 г.)

Получены образцы композитов на основе полистирола с добавлением алюмосиликатов - галлуазитных нанотрубок, слюды Міса и монтмориллонита. Исследовано влияние этих наполнителей на вязкоупругие, механические и структурные свойства композитов. Показано, что при введении алюмосиликатов в виде включений Міса до 5\% можно повысить жесткость композитов и сохранить их прочность на уровне чистого полистирола без сильного охрупчивания образцов. Введение галлуазитных нанотрубок и монтмориллонита, также приводит к повышению жесткости композитов, однако при этом снижается прочность и эластичность материалов. Существенное возрастание модуля упругости композита на изгиб (вплоть до 50\%) было достигнуто при введении 15\% галлуазитных нанотрубок или 5\% Mica.

DOI: $10.21883 / J T F .2019 .02 .47078 .241-18$

\section{Введение}

Широкое использование полимерных материалов в различных отраслях промышленности обусловлено их уникальными характеристиками, такими как малый вес, гибкость в комбинации с достаточной жесткостью, а также простота изготовления деталей сложной формы. Кроме того, чрезвычайно привлекательной является возможность изменения базовых свойств полимерных материалов путем введения в них дисперсных наполнителей.

Недавние теоретические исследования аморфных систем с помощью случайных матриц показали, что добавление небольшой концентрации жестких включений в относительно мягкую аморфную матрицу может привести к существенному увеличению макроскопической жесткости такой системы $[1,2]$. Как было показано ранее, существенное влияние на макроскопическую жесткость аморфных систем оказывает неаффинность смещений атомов при деформации системы [3]. Поскольку характерный масштаб неаффинных смещений оценивается десятками межатомных расстояний [4], то можно ожидать, что частицы нанометрового размера должны оказывать наиболее существенное влияние на макроскопическую жесткость аморфных и полимерных матриц.

Композиционные материалы с наноразмерными включениями, вплоть до единиц микрометров, приобретают новые характеристики, не достижимые при использовании более крупных частиц [5-8]. Однако положительные эффекты возможны лишь при условии однородного распределения включений в матрице и хорошего адгезионного взаимодействия между компонентами композита.
Одним из наиболее многочисленных и разнообразных видов композитных материалов являются композиты на основе полимерных матриц. В течение последних 20 лет работы по улучшению механических свойств полимерных материалов за счет разнообразных добавок являются наиболее активно развивающимся направлением разработки новых композитных материалов. В качестве добавок используются углеродные нанотрубки, графит, графен, фуллерены, нановолокна, частицы металлов, алюмосиликаты и др. (см. например, обзоры [9-11]). В силу своих размеров и высокого поверхностного натяжения наночастицы часто агрегируют в объеме полимерной матрицы [6]. Свойства полимеров с наноразмерными включениями во многом зависят от концентрации, формы, активности поверхности наполнителя, характера его распределения в полимере и взаимодействия с ним, а также от структуры поверхностного слоя наполнителя $[5,6,12,13]$.

Алюмосиликаты обладают большим потенциалом для создания новых материалов и являются перспективными наполнителями для полимерных композитов. Однако природные глинистые минералы и цеолиты являются сложными и непостоянными по составу многокомпонентными системами. Их физико-химические свойства существенно зависят от содержания основной фазы в породе, типа катионообменной формы и характера примесей. Эти обстоятельства ограничивают более широкое использование глинистых минералов в ряде областей, где необходимо постоянство структурных и физикохимических характеристик материала [11].

Первые попытки создания композитов на основе полимеров и алюмосиликатов были предприняты 
в 50-х г. прошлого столетия $[14,15]$. Однако введение до 40-50wt.\% глин (бентонит, гекторит и др.) не привело к улучшению свойств материала, прежде всего из-за неудовлетворительного диспергирования силикатного наполнителя. Значительный прогресс в создании полимер-силикатных нанокомпозитов с улучшенными физическими и механическими свойствами по сравнению с исходными полимерами и традиционными дисперсно-наполненными композитами был достигнут лишь в 90-х годах, после того, как в исследовательской лаборатории Тойота был создан композитный материал на базе нейлона 6 с добавками частиц глины [16], и было продемонстрировано увеличение модуля Юнга, предела прочности на разрыв и теплостойкости материала без потери его ударной прочности [17-19]. Было показано, что наибольшие изменения физико-химических свойств можно ожидать при введении в полимерную матрицу анизометричного наноразмерного наполнителя [20]. Значительной анизометрией обладают, как известно, частицы слоистых алюмосиликатов, в частности, монтмориллонит или галлуазитные нанотрубки.

Полимерные нанокомпозиты находят широкое применение в таких отраслях промышленности, как космическое, авиа- и автомобилестроение, где они подвергаются различным динамическим нагрузкам. Поэтому информация о динамических механических характеристиках этих материалов чрезвычайно важна для оценки их работоспособности.

Многие аморфные полимеры, в частности, полистирол (ПС), полиметилметакрилат (ПММА) и поликарбонат (ПК) имеют ярко выраженные нелинейно упругие свойства. Эти свойства, в частности, допускают формирование в волноводах из этих материалов объемных нелинейных уединенных волн (солитонов) деформации $[21,22]$. Возможность формирования в материале солитона деформации определяется коэффициентом нелинейности [23], который является комбинацией упругих модулей второго и третьего порядка материала. Таким образом, информация об упругих характеристиках важна для корректного предсказания возникновения и эволюции нелинейных волн деформации в этом материале. Поскольку добавление в полимерную матрицу наноматериалов существенно меняет упругие свойства материала, можно ожидать также заметного изменения параметров формирующегося в нем солитона деформации.

Целью настоящей работы являлось создание по расплавной технологии композитов на основе термопластичной полимерной матрицы, наполненной алюмосиликатными нановключениями различной формы. Было исследовано влияние типа и концентрации наполнителя на физико-механические свойства образцов композитов.

\section{Материалы и методы исследования}

В качестве матрицы для композитов использовался ПС марки 585 производства ОАО „Нижнекамскнефте- хим“. Наполнителями служили включения алюмосиликатов различной формы:

- HNT tubes, галлуазитные нанотрубки с диаметром около $100 \mathrm{~nm}$ и длиной от $500 \mathrm{~nm}$ до $1.2 \mu \mathrm{m}$;

- Mica ME-100 (CBC Co. Ltd, Tokyo, Japan), гидрофильная набухающая слюда с катионообменной емкостью (СЕС) $120 \mathrm{me} / 100 \mathrm{~g}$ и средним размером частиц $1-5 \mu \mathrm{m}$;

- MMT Cloising 15A (Southern Clay Products Inc., Texas, United States), монтмориллонит, слоистый силикат с характерным размером частиц $<10 \mu \mathrm{m}$.

Изготовление блочных образцов композитов на основе ПС с включениями алюмосиликатов производилось по расплавной технологии с использованием двухшнекового микрокомпаундера DSM Xplore $5 \mathrm{ml}$ Microcompounder, производства DSM Xplore (Нидерланды). Смешение осуществлялось при температуpe $220^{\circ} \mathrm{C}$ в течение $5 \mathrm{~min}$ и скорости вращения шнеков $\omega=50 \mathrm{~min}^{-1}$. Затем происходило формование блочных образцов путем впрыскивания расплава полимера в пресс-форму, нагреваемую до $80^{\circ} \mathrm{C}$. В зависимости от типа пресс-формы были получены блочные образцы композитов двух видов: пластины размером $50 \times 10 \times 1.5 \mathrm{~mm}$ и лопатки с длиной в рабочей зоне $20 \mathrm{~mm}$, шириной $4 \mathrm{~mm}$ и толщиной $1.5 \mathrm{~mm}$. Затем пресс-форма вынималась из микроинжектора и охлаждалась до комнатной температуры на воздухе. Таким образом, были получены блочные образцы из чистого ПС и композитов с включениями алюмосиликатов. Концентрации наполнителей составляли $K=1,3,5,10$ и $15 \mathrm{wt} . \%$.

Реологические характеристики расплавов композитов определялись с помощью реометра Physica MCR 301 (Anton Paar $\mathrm{GmbH}$, Австрия) в измерительном узле конус-плоскость СР25-2 при $220^{\circ} \mathrm{C}$ в сдвиговом и динамическом (колебательном) режимах со снижением (Down) и ростом (Top) скорости деформации (круговой частоты) в воздушной атмосфере.

Особенности морфологии композитов на основе ПС и включений из алюмосиликатов различной формы изучались по микрофотографиям поверхности крио-сколов образцов композитов с использованием сканирующего электронного микроскопа (СЭМ) Supra-55 (Carl Zeiss, Германия). Для получения поперечных сколов образцы закреплялись в держателе и на несколько секунд погружались в жидкий азот. После охлаждения производился резкий отрыв свободного конца образца с образованием скола по плоскости, перпендикулярной длине пластины. Полученные образцы приклеивались на специальный столик. Для снятия заряда статического электричества и улучшения контраста на исследуемую поверхность проводилось напыление золота. После этого столик с образцами загружался в рабочую камеру микроскопа, и производилось сканирование поверхности сколов образцов электронным пучком.

Исследование влияния включений алюмосиликатов на механические свойства полученных композитов осу- 
ществлялось с помощью одноосного растяжения и динамических механических испытаний на трехточечный изгиб. Образцы композитов подвергались одноосному растяжению с помощью универсальной разрывной машины 1958-У10-1 (Россия) при базовой длине $25 \mathrm{~mm}$ и скорости растяжения $1 \mathrm{~mm} / \mathrm{min}$. На основе диаграмм растяжения были определены значения прочности $\sigma_{p}$, относительного удлинения $\varepsilon$ и модуля упругости $E$. Для проведения данных испытаний использовались лопатки, полученные по описанной выше технологии, с длиной в рабочей зоне $20 \mathrm{~mm}$, шириной $4 \mathrm{~mm}$ и толщиной $1.5 \mathrm{~mm}$. Динамический механический анализ на трехточечный изгиб проводился на установке DMA 242 C (Netzsch, Германия) при частоте $1 \mathrm{~Hz}$ и динамической силе $2 \mathrm{H}$. Расстояние между опорами составляло $25 \mathrm{~mm}$. На основе полученных данных определялся модуль упругости на изгиб $E^{\prime}$. Для испытаний использовались композиты в виде пластин с размером $50 \times 10 \times 1.5 \mathrm{~mm}$.

\section{Результаты и их обсуждение}

\section{Реологические характеристики расплавов композитов ПС-алюмосиликатные включения}

Чтобы выяснить влияние формы и концентрации алюмосиликатных включений на реологические характеристики расплава ПС-матрицы были проведены реологические исследования. Полученные данные представлены на рис. 1-5. Отметим, что расплавы исследуемых композитов демонстрировали стабильные реологические характеристики в течение всего эксперимента (60 min).

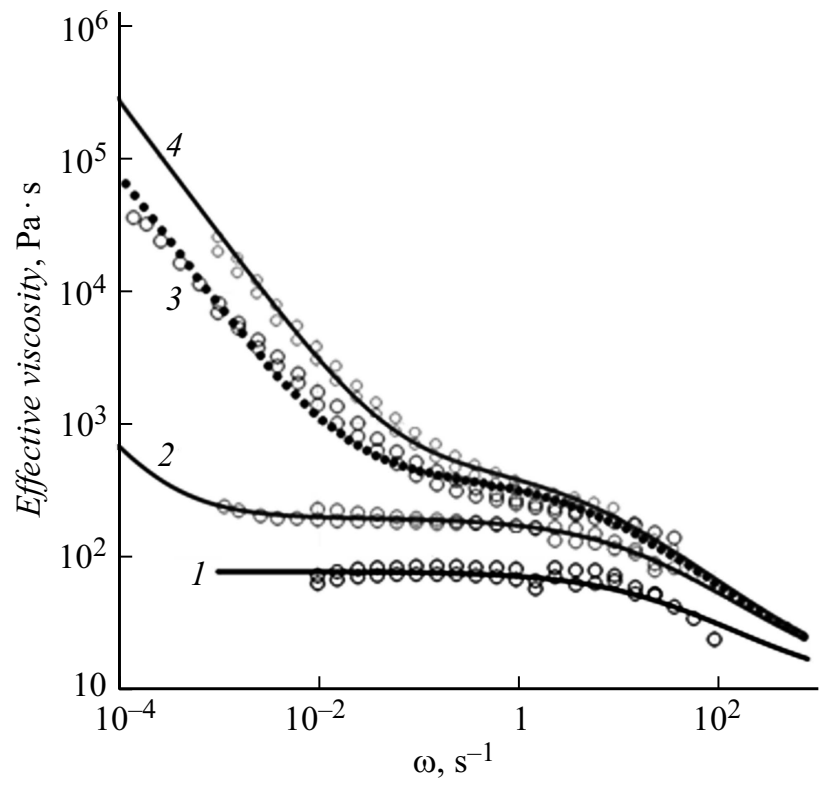

Рис. 1. Зависимость вязкости расплава от скорости сдвига для композитов на основе ПС с различной концентрацией MМТ: 1 - чистый ПС; $2-1$ wt.\% ММТ; $3-3$ wt.\% ММТ и 4-5 wt.\% ММТ. Кружки - экспериментальные данные, линии - аппроксимация.

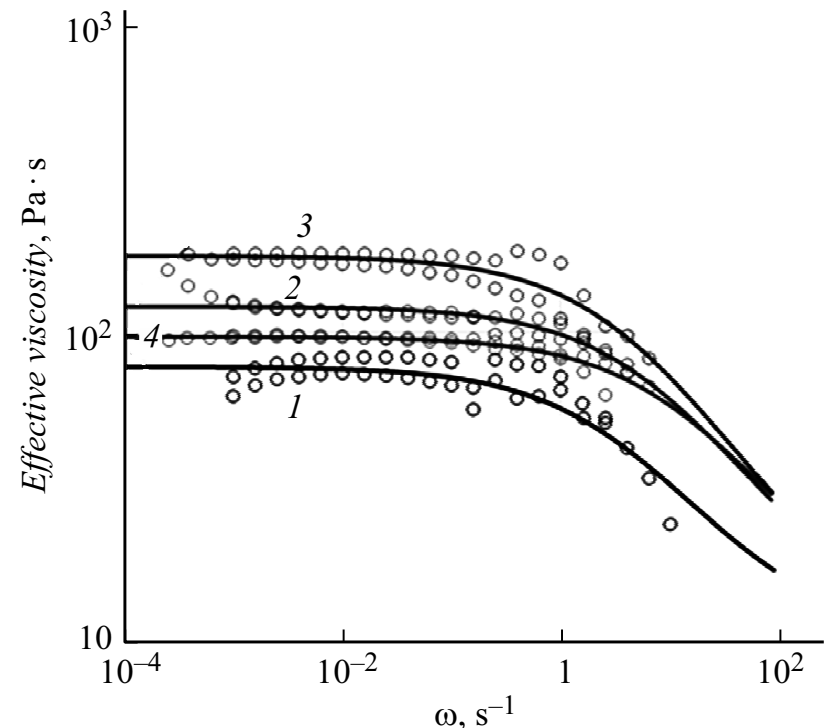

Рис. 2. Зависимость вязкости расплава от скорости сдвига для композитов на основе ПС с различной концентрацией Mica: 1 - чистый ПС; $2-1 \mathrm{wt} . \%$ Mica; $3-3 \mathrm{wt} . \%$ Mica и 4-5 wt.\% Mica. Кружки - экспериментальные данные, линии - аппроксимация.

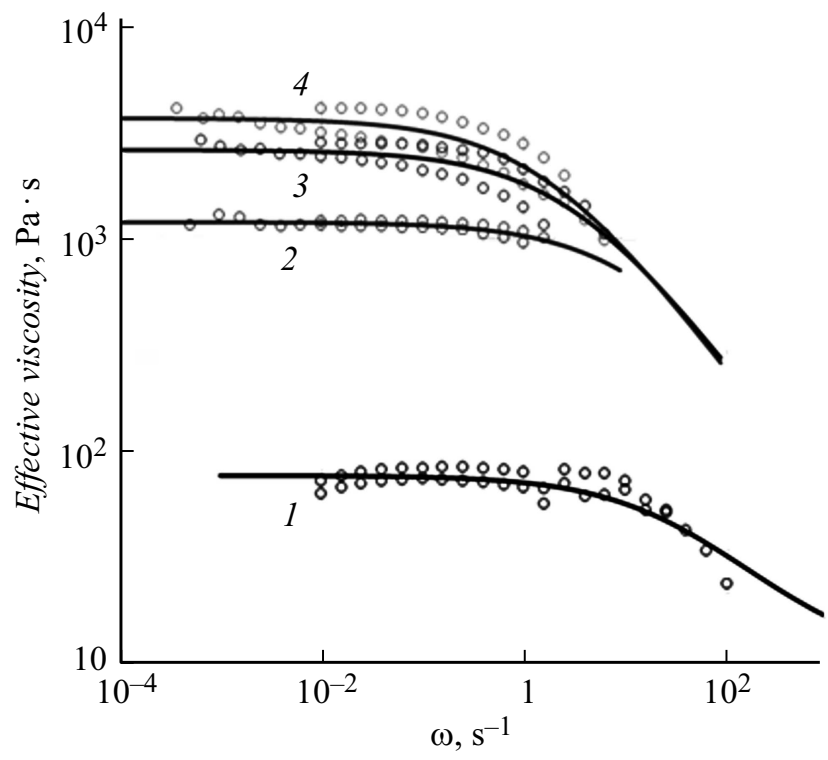

Рис. 3. Зависимость вязкости расплава от скорости сдвига для композитов на основе ПС с различной концентрацией HNT: 1 - чистый ПС; 2 - 5wt.\% HNT; 3 - 10 wt.\% HNT и $4-15$ wt.\% HNT. Кружки - экспериментальные данные, линии - аппроксимация.

Расплав ненаполненного ПС не подчиняется правилу Кокса-Мерца и является неньютоновской жидкостью. Вязкость в сдвиговом режиме равна динамической вязкости (действительная часть комплексной вязкости) при равенстве значений скорости деформации и круговой частоты. 


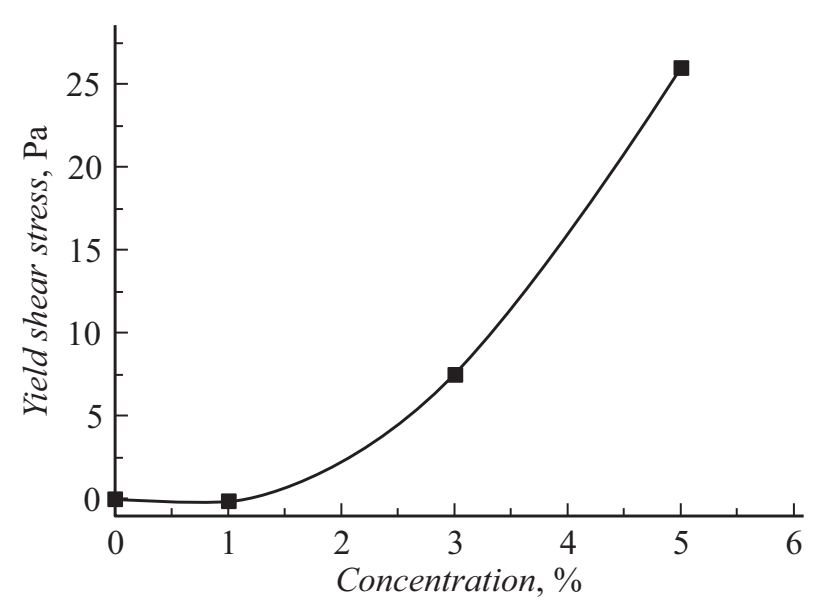

Рис. 4. Условный предел текучести, рассчитанный при заданной наименьшей ньютоновской вязкости $(10 \mathrm{~Pa} \cdot \mathrm{s})$ в зависимости от содержания ММТ.

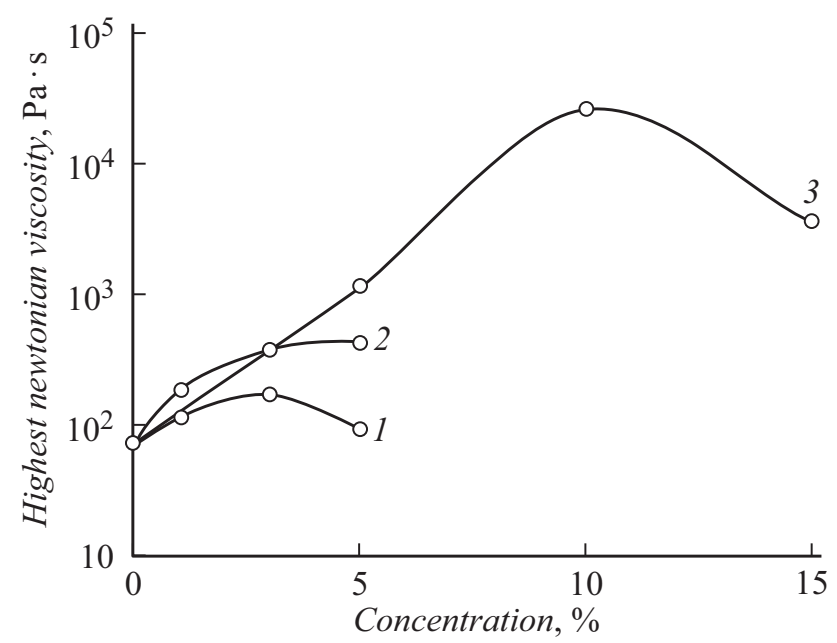

Рис. 5. Наибольшая ньютоновская вязкость, рассчитанная при заданной наименьшей ньютоновской вязкости $(10 \mathrm{~Pa} \cdot \mathrm{s})$ в зависимости от содержания включений: $1-$ ПС + Mica, $2-\Pi \mathrm{C}+\mathrm{MMT}, 3-\Pi \mathrm{C}+\mathrm{HNT}$.

Из рис. 1-3 видно, что все исследуемые композиты на основе ПС с алюмосиликатными включениями также являются неньютоновскими жидкостями. Введение включений приводит к увеличению вязкости расплава пропорционально концентрации наполнителя, за исключением композитов с 5 wt.\% Mica. Наибольший эффект наблюдается при введении ММТ. Эффективная вязкость при 5 wt.\% ММТ возрастает на 4 порядка по сравнению с чистым ПС. Увеличение вязкости расплавов при низких скоростях сдвига свидетельствует о формировании сеточной структуры между полимером и наполнителями, что подтверждается рис. 4 и данными [24,25]. Увеличение содержания ММТ приводит к упрочнению надмолекулярной структуры (росту условного предела текучести) и повышению наибольшей ньютоновской вязкости за счет образования сольватных оболочек свя- зующего на частицах включений. Вязкость расплавов композитов ПС + ММТ находится в технологическом диапазоне скоростей деформации $\left(0.1-100 \mathrm{~s}^{-1}\right)$ и достигает $3000 \mathrm{~Pa} \cdot \mathrm{s}$ за счет формирования надмолекулярной структуры.

В случае введения частиц Міса вязкость расплава композита не превышает $180 \mathrm{~Pa} \cdot \mathrm{s}$ в технологическом диапазоне скоростей деформации, но остается достаточной для переработки данного композита по расплавному методу. При концентрации включений Mica и ММТ более 5 wt.\% наблюдается насыщение, которое приводит к снижению дальнейшего роста наибольшей ньютоновской вязкости (рис. 5).

При введении HNT такой эффект наблюдается при концентрации включений более $10 \mathrm{wt} \%$ (рис. 5). Стоит отметить, что вязкость расплава композита с $15 \mathrm{wt} . \%$ $\mathrm{HNT}$ достигает $3800 \mathrm{~Pa} \cdot \mathrm{s}$ (рис. 3) в технологическом диапазоне скоростей деформации, что затрудняет изготовление композитов по расплавному методу.

\section{Структура композитов ПС-алюмосиликатные включения}

На рис. 6 и 7 представлены микрофотографии поверхности поперечных крио-сколов блочных образцов чистого ПС и композитов на его основе.

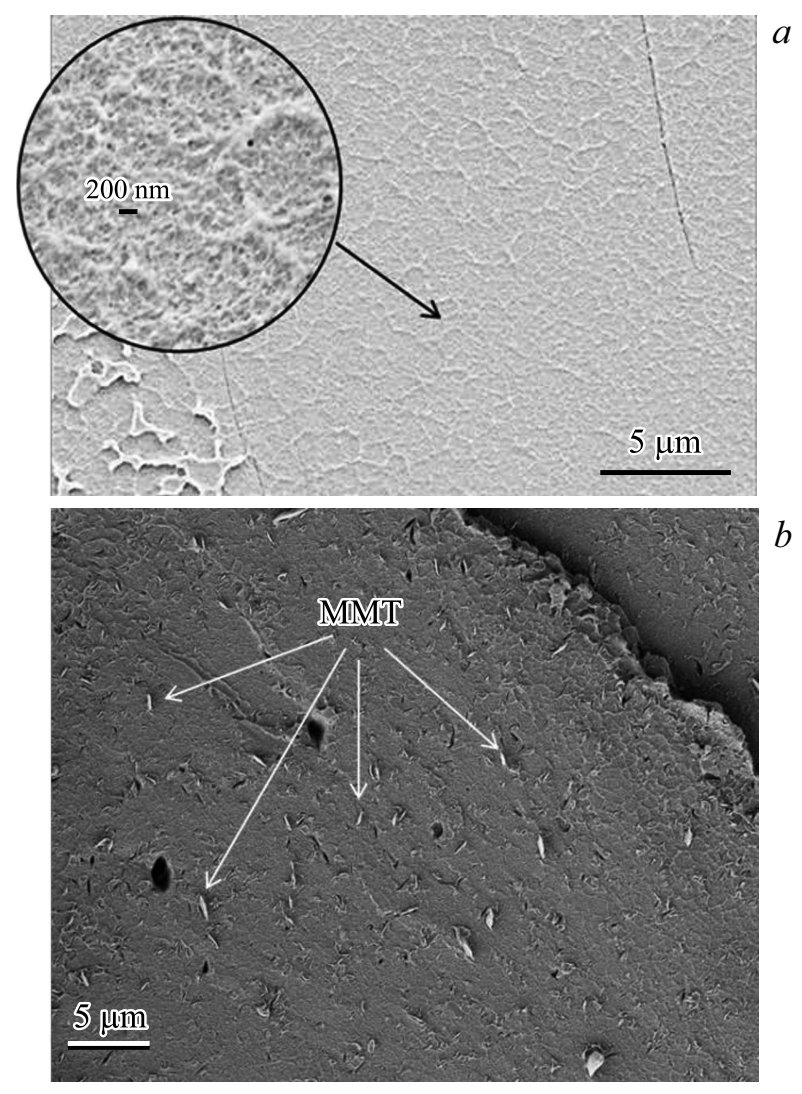

Рис. 6. Микрофотографии поверхности криосколов блочных образцов из чистого полистирола $(a)$ и композита $\Pi \mathrm{C}+3$ wt. $\%$ MMT $(b)$. 

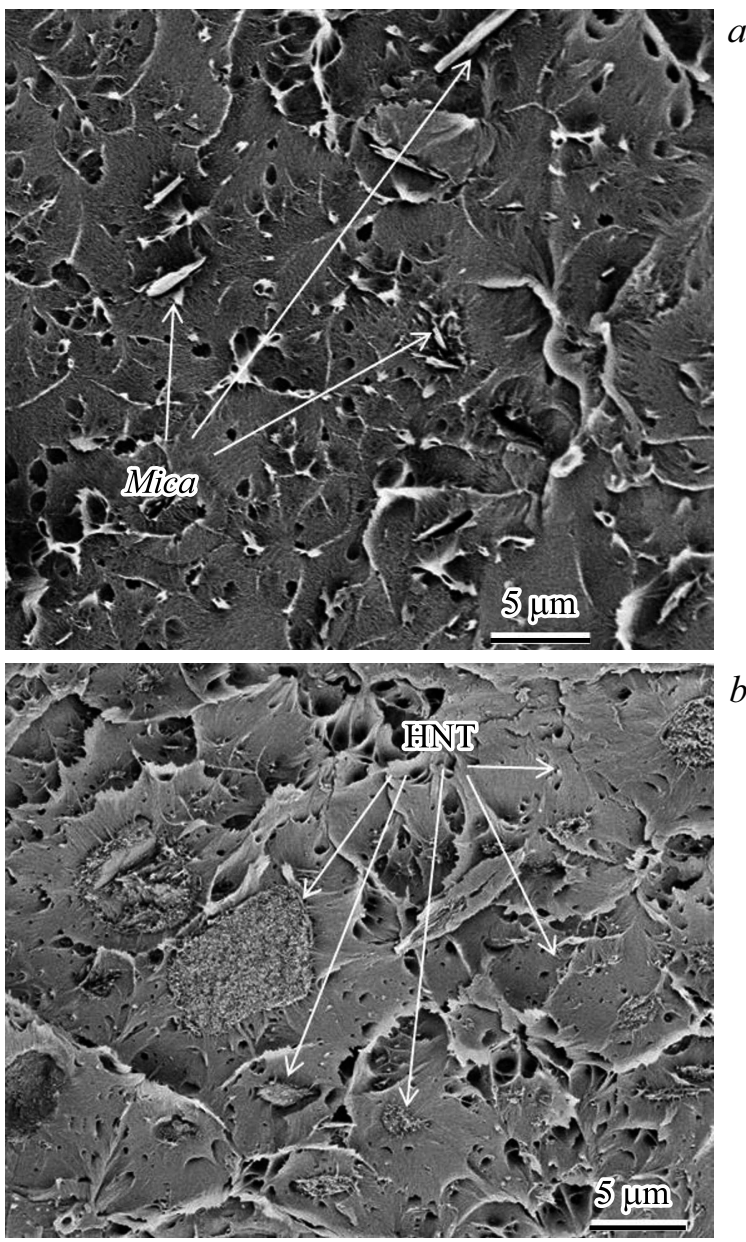

Рис. 7. Микрофотографии поверхности криосколов блочных образцов из композитов ПС $+3 \mathrm{wt} . \%$ Mica $(a)$ и $\Pi \mathrm{C}+10 \mathrm{wt} . \% \mathrm{HNT}(b)$.

Как видно из приведенных микрофотографий, включения Міса и ММТ достаточно равномерно распределяются в объеме ПС-матрицы в виде небольших агрегатов с размером до $1-2 \mu \mathrm{m}$ (рис. $6, b, 7, a)$. Однако добиться получения композита с интеркалированной структурой данным способом не удалось. Вероятно, помимо механического смешения необходимо использовать дополнительные технологические операции, повышающие совместимость полимера со слоистым силикатом (например, модифицирование алюмосиликатных включений органическими катионами) [26-29]. Галлуазитные нанотрубки при введении в малых концентрациях распределяются в объеме ПС-матрицы в виде отдельных частиц с диаметром $\sim 100 \mathrm{~nm}$ и длиной до $1 \mu \mathrm{m}$ (рис. 7, $b$ ). При концентрации $10 \mathrm{wt} . \%$ появляются агрегаты эллипсообразной формы со средним размером $5 \mu \mathrm{m}$. Это обусловлено тем, что, как было показано при реологическом исследовании, при данной концентрации HNT вязкость расплава существенно возрастает, что осложняет качественное диспергирование включений в расплаве ПС-матрицы.

\section{Механические свойства композитов ПС-алюмосиликатные включения}

Влияние формы и концентрации алюмосиликатных включений на механические свойства ПС-композитов определялось на основе одноосного растяжения и динамического механического анализа на трехточечный изгиб по описанным выше методикам. В таблице представлены значения основных механических характеристик композитов на основе ПС и алюмосиликатных включений, полученных на основе диаграмм растяжения.

Отметим, что при испытании на растяжение для образцов из чистого ПС и композита, наполненного до $5 \mathrm{wt} . \%$ Mica, характерно пластическое разрушение с наличием области условного предела текучести на диаграмме растяжения. В то же время для композитов с HNT и MMT наблюдается хрупкое разрушение вне зависимости от концентрации включений. Экспериментальные данные согласуются с результатами, полученными другими авторами для различных термопластичных матриц и исследуемых включений [30-33].

Введение частиц Міса приводит к повышению модуля упругости композита и при максимальном наполнении 5 wt.\% достигает $1.9 \mathrm{GPa}$, в то время как для чистого ПС он составляет $1.6 \mathrm{GPa}$. При этом удлинение до разрыва снижается на $30 \%$ и достигает значения 3.9\%. Стоит отметить, что прочность композитов с включениями Міса не зависит от концентрации и остается на уровне чистого ПС $\left(\sigma_{p}=56 \mathrm{MPa}\right)$.

Введение включений HNT вызывает повышение модуля упругости аналогично Мica. Однако при введении данного наполнителя не удается достичь повышения модуля жесткости при концентрации наполнителя 5 wt.\%, значение $E=2 \mathrm{GPa}$ достигается при наполнении HNT порядка $10 \mathrm{wt} . \%$. Дальнейшее увеличение концентрации включений не приводит к росту модуля упругости. При этом удлинение снижается на $60 \%$, а прочность почти на $20 \%$.

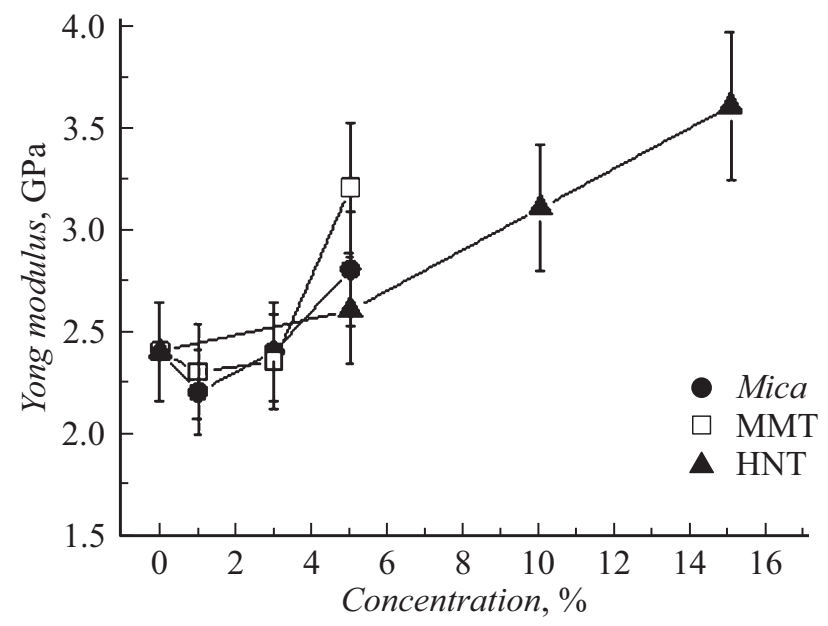

Рис. 8. Зависимость модуля упругости ПС композитов от типа и концентрации алюмосиликатного наполнителя при испытании образцов на трехточечный изгиб методом ДМА. 
Механические свойства композитов на основе ПС и включений Мica, HNT и MMT, полученные из диаграмм растяжения

\begin{tabular}{|c|c|c|c|}
\hline Образец & $\begin{array}{c}\text { Предел прочности, } \\
\text { МРа }\end{array}$ & $\begin{array}{c}\text { Модуль упругости, } \\
\text { GPa }\end{array}$ & $\begin{array}{c}\text { Относительная } \\
\text { деформация при } \\
\text { разрушении, \% }\end{array}$ \\
\hline 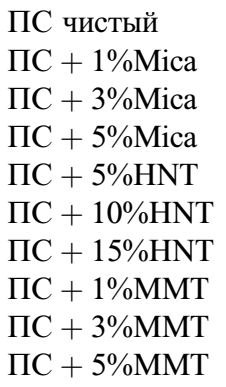 & $\begin{array}{l}56 \pm 1 \\
56 \pm 4 \\
54 \pm 2 \\
56 \pm 5 \\
52 \pm 1 \\
49 \pm 6 \\
46 \pm 4 \\
58 \pm 4 \\
50 \pm 4 \\
46 \pm 2\end{array}$ & $\begin{array}{r}1.6 \pm 0.1 \\
1.84 \pm 0.02 \\
1.86 \pm 0.04 \\
1.94 \pm 0.05 \\
1.68 \pm 0.15 \\
2.0 \pm 0.06 \\
2.08 \pm 0.09 \\
1.85 \pm 0.04 \\
1.89 \pm 0.04 \\
1.93 \pm 0.07\end{array}$ & $\begin{array}{l}5.6 \pm 0.2 \\
4.4 \pm 0.13 \\
4.1 \pm 0.21 \\
3.9 \pm 0.3 \\
5.7 \pm 0.3 \\
2.8 \pm 0.5 \\
2.4 \pm 0.2 \\
3.9 \pm 0.4 \\
2.9 \pm 0.3 \\
2.6 \pm 0.2\end{array}$ \\
\hline
\end{tabular}

Влияние частиц ММТ на механические свойства композитов из ПС аналогично HNT. Уже при концентрации $5 \mathrm{wt} \%$ ММТ прочность образцов снижается с 56 до $46 \mathrm{MPa}$, а удлинение с 5.6 до $2.6 \%$. Модуль упругости при этом наполнении достигает максимального значения $E=1.9 \mathrm{GPa}$.

Таким образом, при введении алюмосиликатов в виде включений Міса до 5\% удается повысить жесткость композитов и сохранить их прочность на уровне чистого ПС без сильного охрупчивания образцов. Введение других типов включений (HNT и МMT) хоть и приводит к повышению жесткости композитов, но при этом снижается прочность и эластичность материалов.

Для большинства изделий из полимерных материалов важно не только обеспечить их способность сопротивляться деформированию при растяжении, но и сохранять надежность конструкции при действии изгибающих нагрузок. Было проведено исследование влияния типа и концентрации алюмосиликатных включений на значение модуля упругости при изгибе (рис. 8).

Как видно из рис. 8, введение в объем полимерной матрицы более жестких частиц приводит к росту модуля упругости композита на изгиб с увеличением концентрации включений. Так, при 5\% Міса наблюдается резкое возрастание модуля упругости ПС-композита от уровня ненаполненного полимера $\left(E^{\prime}=2.4 \mathrm{GPa}\right)$ до значений $3.2 \mathrm{GPa}$. Максимальное полученное увеличение на 50\% модуля упругости при изгибе было получено при введении 15\% HNT. Введение меньших концентраций не приводит к возрастанию $E^{\prime}$, и его значение остается на уровне чистого ПС $E^{\prime}=2.4 \mathrm{GPa}$. Значения $E^{\prime}$ для композитов ПС + ММТ имеют средние значения между образцами, наполненными Mica и HNT.

В отличие от исследованных нами ранее композитов на основе ПММА и ПС-матриц с нановключениями модифицированных силазаном наночастиц $\mathrm{SiO}_{2}$ [34] композиты на основе ПС с включениями алюмосиликатов обладают повышенным значением модуля упругости при меньших концентрациях нановключений (5\% Mica и $15 \% \mathrm{HNT}$ ), в то время как $\mathrm{SiO}_{2}$ необходимо вводить около 20\%. Сами же максимально достигнутые значения модуля упругости для исследуемых композитов ПС с нановключениями различной геометрической формы находятся примерно на одном уровне, около $3.2 \mathrm{GPa}$.

\section{Заключение}

Таким образом, в работе по расплавной технологии были получены образцы композитов на основе полистирольной полимерной матрицы с добавлением включений алюмосиликатов различной формы. Были проведены исследования реологических характеристик расплавов композитов и контроль равномерности распределения включений в композите при разных концентрациях наполнителей. Вязкоупругие свойства образцов исследовались методом ДМА. Механические свойства образцов исследовались при испытаниях на одноосное растяжение и трехточечный изгиб. Было показано, что при введении алюмосиликатов в виде включений Мica до 5\% удается повысить жесткость композитов и сохранить их прочность на уровне чистого ПС без сильного охрупчивания образцов. Введение других типов включений (HNT и ММТ) хоть и приводит к повышению жесткости композитов, но при этом снижается прочность и эластичность материалов. Существенное возрастание модуля упругости композита на изгиб (вплоть до 50\%) было достигнуто при введении 15\% галлуазитных нанотрубок или $5 \%$ Mica.

Полученные результаты позволят в дальнейшем провести исследования нелинейно-упругих свойств синтезированных композитов, в частности, изучить формирование и эволюцию в них объемных нелинейных волн деформации. Такие волны перспективны для разработки методик неразрушающего контроля и дефектоскопии функциональных и конструкционных элементов, выполненных из композитных материалов.

ОАМ, ИВС и ЯМБ благодарят Российский научный фонд за финансовую поддержку исследования в рамках гранта № 17-72-20201. 


\section{Список литературы}

[1] Beltukov Y.M., Kozub V.I., Parshin D.A. // Phys. Rev. B. 2013. Vol. 87. P. 134203.

[2] Бельтюков Я.М., Паршин Д.А. // Письма в ЖЭТФ. 2016. T. 104. C. 570.

[3] Beltukov Y.M., Parshin D.A. // Письма в ЖЭТФ. 2011. Т. 93. C. 660.

[4] Leonforte F., Boissiere R., Tanguy A.J., Wittmer P., Barrat J.-L. // Phys. Rev. B. 2005. Vol. 72. N 22. P. 224206.

[5] Пул Ч., Оуэнс Ф. Нанотехнологии. М.: Техносфера, 2004. $327 \mathrm{c}$.

[6] Vian R.A., Maguire J.F. // Chem. Mater. 2007. Vol. 19. P. 2736-2751.

[7] Njugunal J., Pielichowski K., Desai S. // Polym. Adv. Technol. 2008. Vol. 19. P. 947-959.

[8] Серенко О.А., Лущейкин Г.А., Гетманова Е.В., Гриценко О.Т., Музафаров А.М. // ЖТФ. 2011. Т. 81. Вып. 9. C. 63-66.

[9] Hanemann T., Szabó D.V. // Materials. 2010. N 3. P. 3468-3517.

[10] Papageorgiou D.G., Kinloch I.A., Young R.J. // Progr. Mater. Sci. 2017. Vol. 90. P. 75-127.

[11] Lopes P., Martins A.C., Lanceros-Mendez S. // Progr. Surf. Sci. 2014. Vol. 89. P. 239-277.

[12] Юрков Г.Ю., Фионов А.С., Кокшаров Ю.А., Колесов В.В., Губин С.П. // Неорган. материалы. 2007. Т. 43. № 8. C. $936-947$.

[13] Гладченко С.В., Полочкая Г.А., Грибанов А.В., Знонник В.Н. // ЖТФ. 2002. Т. 72. Вып. 1. С. 105-109.

[14] US patent 2531396. 1956. National Lead Co.2.

[15] US patent 3084117. 1963. Union Oil Co.

[16] Kojima Y., Usuki A., Kawasumi M., Okada A., Fukushima Y., Kurauchi T. et al. // J. Mater. Res. 1993. N 8. P. 1185-1189.

[17] Kojima Y., Usuki A., Kawasumi M., Okada A., Kurauchi T., Kamigaito O. // J. Polym. Sci. A. 1993. Vol. 31. P. 1755.

[18] Kojima Y., Usuki A., Kawasumi M., Okada A., Kurauchi T., Kamigaito O. // J. Appl. Polym. Sci. 1993. Vol. 49. P. 1259.

[19] Yano K., Usuki A., Okada A., Kurauchi T., Kamigaito O. // J. Polym. Sci. A. 1993. Vol. 31. P. 2493.

[20] Чвалун С.Н., Новокшонова Л.А., Коробко А.П., Бревнов П.Н. // РХЖ. (журн. Рос. хим. об-ва им. Д.И. Менделеева). 2008. T. LII. № 5. С. 52-57.

[21] Дрейден Г.В., Самсонов А.М., Семенова И.В. // ЖТФ. 2008. Т. 78. Вып. 5. С. 8-14.

[22] Дрейден Г.В., Самсонов А.М., Семенова И.В. // Письма в ЖТФ. 2011. Т. 37. Вып. 11. С. 20-26.

[23] Samsonov A.M. Strain Solitons in Solids and how to construct them. London, N Y: Chapman \& Hall/CRC Press, Boca Raton, 2001. 248 p.

[24] Naira K.C., Kumara R.P., Thomasa S., Schitb S.C., Ramamurthy K. // Composites Part A: Appl. Sci. Manufactur. 2000. Vol. 31. N 11. P. 1231-1240.

[25] Gelfer M.Y., Song H.H., Liu L., Hsiao B.S., Chu B., Rafailovich M., Si M., Zaitsev V. // J. Polym. Sci. Part B: Po lym. Phys. 2003. Vol. 41. N 1. P. 44-54.

[26] Hao Li, Yunzhao Yu, Yukun Yang // Europ. Polym. J. 2005. Vol. 41. N 9. P. 2016-2022.

[27] Manias E., Touny A., Wu L., Strawhecker K., Lu B., Chung T.C. // Chem. Mater. 2001. Vol. 13. P. 3516.

[28] Kawasumi M., Hasegawa N., Kato M., Usuki A., Okada A. // Macromolecules. 1997. Vol. 30. P. 6333.
[29] Vaia R.A., Sauer B.B., Tse O.K., Giannelis E.P. // J. Polym. Sci. B. 1997. Vol. 35. P. 59-67.

[30] Daoji Gan, Shiqiang Lu, Caisheng Song, Zhijian Wang // Europ. Polym. J. 2001. Vol. 37. 7. P. 1359-1365.

[31] Nan-ying Ning, Qin-jian Yin, Feng Luo, Qin Zhang, Rongni Du, Qiang Fu. // Polymer. 2007. Vol. 48. N 25. P. 7374-7384.

[32] Prashantha K., Lacrampe M.F., Krawczak P. // Polym. Lett. 2011. Vol. 5. N 4. P. 295-307.

[33] Cyrasa V.P., Manfredia L.B., Ton-Thatb M.-T., Vázquez A. // Carbohydrate Polym. 2008. Vol. 73. N 1. P. 55-63.

[34] Москалюк О.А., Самсонов А.М., Семенова И.В., Смирнова В.Е., Юдин В.Е. // ЖТФ. 2017. Т. 87. Вып. 2. С. 106-110. 